\title{
Sources and Eco-toxicological Effects of Ultrafine Particle Matters
}

\author{
SHAN Huimei ${ }^{1}$, LUO Linbo ${ }^{2,3}$, WANG Shaopei ${ }^{2}$, LIAO Danxue ${ }^{1}$, ZHAO Chaoran $^{1}$, PENG Sanxi ${ }^{4 *}$ \\ ${ }^{1}$ College of Environmental Science and Engineering, Guilin University of Technology, Guilin 541004, China; \\ ${ }^{2}$ Wuhan East Lake Innovation Base Co., Ltd. Wuhan 430074, China; \\ ${ }^{3}$ China University of Geosciences, Wuhan 430074, China; \\ ${ }^{4}$ College of Eerth Science, Guilin University of Technology, Guilin 541004, China;
}

\begin{abstract}
Environmental air pollution has become an important threat to human health. As one of the major air pollutants, atmospheric particulates have received attention widely. In which, ultrafine particulate matters (UPM) with diameter below $0.1 \mu \mathrm{m}$ have become the main components of ambient air particulates, posing a serious threat to the health of the organism. Therefore, this paper investigated and summarized the research on ultrafine particles at home and abroad, systematically analysed the sources of UPM in ambient air, investigated its toxicological effects of ultrafine particles on the respiratory system, cardiovascular system, and central nervous system of organisms. This study will provide a theoretical reference for environmental air protection and pollution control in China.
\end{abstract}

\section{Introduction}

Air pollution has been paid more and more Attention. World health organization has listed pollutants in the air as "one of the most dangerous environmental carcinogens ". Particulate matter (PM), as one of the main pollutants in the air, can cause the greatest health threat. It can adsorb a large number of carcinogenic substances and genotoxic mutagenic substance, so that the exacerbation of chronic diseases, respiratory and heart system disease deterioration, changing lung function and structure, affecting reproductive capacity, changing the body's immune structure, and significantly improve mortality $[1 \sim 3]$.

In the 1980s, PM10 (particle size below $10 \mu \mathrm{m}$ ) was first adopted by the United States as an important control indicator of air quality standards. Since the 90 s, countries like European and American have successively carried out researches on the physicochemical characterization, atmospheric chemical process, and health effect and climate impact of atmospheric PM2.5 (particle size below $2.5 \mu \mathrm{m}$ ). Research on the toxicological effects of PM found: smaller the PM size, greater the likelihood of serious impacts on the environment and human health [4]. Therefore, more and more scholars began to pay attention to the environmental behavior and treatment of UPM (particle size below $0.1 \mu \mathrm{m}$ ). PM10 and PM2.5 have been used as an indicator of air quality control in the early years in China. However, there is limited understanding of the sources and behavioral characteristics of ultrafine particles in the air, as well as the impact on health.
Based on the existing research results, this paper systematically analyzed the sources of UPM in the air, and investigated the ecological toxicity effects of UPM on the respiratory system, cardiovascular systems and central nervous system of organism. This study will provide a theoretical reference for the UPM behavor research and air pollution treatment in China.

\section{Sources of UPM in the air environment}

There are two pollution sources of UPM in the atmosphere. One is natural, the other is artificial sources. Natural sources include volcanic eruptions, sandstorms, forest and grassland fires, plants and marine sprays, and so on [5]. Volcanic eruption process will produce volcanic ash, sulfur dioxide, sulfate and other particulate matter. Forest and grassland fires release organic carbon particles into the atmosphere through biomass burning. The gases produced during the growth and decay of certain plants react with substances in the air and further form UPM [6]. Sea salt spray is mainly affected by the wind driving force, the spray emits numerous sea salt particles from the waves and is suspended at the interface between the ocean and the air in the form of aerosol [6].

According to the emission characteristics of UPM, its anthropogenic sources of pollution can be divided into indoor sources and outdoor sources. The outdoor sources mainly include transportation exhaust emissions, combustion reactions, dust and so on. The main indoor sources include kitchen cooking, cigarette burning, and laser printer and so on.

\footnotetext{
$\overline{\text { *Corresponding author's e-mail: 2016047@glut.edu.cn }}$
} 
Statistics showed that motor vehicle exhaust was the main outdoor source of UPM, especially in urban environments [7]. Results of UPM at the freeway west of Los Angeles in the United States found that traffic exhaust emissions are the main contributors to UPM on expressways, and the particle size distributions of UPM change with distance [8]. In addition, the traffic dust and particulate matter emissions are closely related. In many cities and rural areas around the world, thermal power generation and residential heating are still dependent on coal, and the resulting particulate matter becomes an important pollution source of UPM in the atmosphere. Study on combustion emission of bituminous coal, subbituminous coal and anthracite showed that the particles released by coal combustion less than $0.49 \mu \mathrm{m}$ account for more than $80 \%$ of the total discharged particles, including Organic Carbon (OC), Elemental Carbon (EC), and Polycyclic Aromatic Hydrocarbons (PAHs) [9]. The particulate generated by the combustion of bituminous coal and lignite also contains a large number of heavy metal elements such $\mathrm{As}, \mathrm{Cr}, \mathrm{Pb}, \mathrm{Se}$ and $\mathrm{Cd}$, and their contents increased with the decrease of particle size [10].

Total particulate exposure assessment shows that cooking is one of the most important indoor sources of UPM, and its concentration increases with cooking time [11]. Regardless of the impact of outdoor pollution, cigarette burning is the second largest source of indoor particulate matter after cooking. The study found that fresh undiluted cigarette smoke contains a large number of particles smaller than $0.05 \mu \mathrm{m}$ toxic nanoparticles [12]. In the process of cigarette burning, the concentration peak of UPM and the density peak of surface area were mainly distributed in the range of $0.0475 \sim 0.0663 \mathrm{~mm}$ and $0.0856 \sim 0.1005 \mathrm{~mm}$ [13]. The concentration test of particulate matter before and after smoking ban in indoor public places showed that after three months of nonsmoking, UPM concentration decreased significantly from $76956 / \mathrm{cm} 3$ to $38079 / \mathrm{cm} 3$ [14]. In the particulates emitted by indoor printers, the particle size below $93.1 \mathrm{~nm}$ takes up more than $92 \%$ of the total particle number, and the particle quantity and mass concentration produced slow attenuation, which has a long-term impact on indoor air quality [15].

\section{Eco-toxicological effects of UPM}

Epidemiological studies have found that mortality was closely related to the composition and concentration of PM in the air, especially UPM. UPM easily enters organisms through breathing or skin contact, participates in various metabolism processes, and produces serious health threats to the respiratory, cardiovascular and central nervous systems of organisms.

\subsection{Effects of UPM on the respiratory system}

Atmospheric particulate exposure level is closely related to chronic obstructive pulmonary disease, bronchitis, asthma and other respiratory diseases, especially in the elderly, children and asthma patients and other susceptible people [16]. UPM can enter the human lungs through the respiratory tract, stimulating the movement of macrophages in the alveoli to produce harmful oxidants and mediators causing lung inflammation and oxidative stress. Because the concentrations of UPM is very high in the environmental air and it shows ultrasmall particle size characteristics, macrophages cannot effectively phagocytose them, eventually stranded in the alveolar, inducing chronic obstructive pulmonary disease and causes damage to respiratory system structure and function.

\subsection{Effects of UPM on cardiovascular system}

The total mortality of cardiopulmonary disease is related to the degree of exposure in UPM [17]. Samet et al. found that acute exposure to high concentrations of UPM can cause the increase of heart rate variability, sympathetic imbalance and break the body's self-balance. In healthy subjects, their change of mild inflammation, thrombosis, and cardiac re-polarization were associated with exposure to UPM. Repeated studies have confirmed a significant positive correlation between long exposure to UPM produced by traffic exhaust and the increase in the hospitalization rate of ischemic stroke. UPM aggravated the atherosclerosis effect of particulate matter in ambient air on healthy subjects, which is an important factor leading to cardiovascular risk. Liu et al. reported that there is a close association between the increased incidence of cardiovascular disease and high concentration of UPM.

\subsection{Effects of UPM on the central nervous system}

It was found that in healthy subjects, the loss of cognitive function was associated with exposure of UPM [18]. The study emphasized that the loss of Brain-Derived Neurotrophic Factor (BDNF) is associated with a large amount of UPM generated by traffic. UPM affects the release of BDNF, which further causes the loss of cognitive and memory functions. Exposure to high concentration of UPM is likely to lead to cognitive decline and depression for children, adults and the elderly. A study of neonatal rats showed that there are toxic effects of UPM in the atmosphere on the central nervous system, in which the neurotoxicity is closely related to emotional behavior, learning ability and the level of brain neurotransmitter.

\subsection{Other effects of UPM on health}

UPM shows strong penetrating force and has a larger specific surface area. Therefore, it can carry a variety of bacteria, viruses, heavy metals, and carcinogenic chemicals to all parts of the human body through the blood circulation and contact with human cells, leading to cell lesions. The study of radioactivity distribution after "Ultrafine carbon particles of Technetium tag" inhaled by healthy volunteers found that significant radioactivity was detected in human blood, lung, liver and bladder within a short time, suggested that UPM 
have a significant impact on the lungs, liver, genitals, inflammatory factors in the blood, and cancer[19].

\section{Conclusions}

This study systematically summarizes the source and ecotoxicological effects of UPM. It was found that: (1) UPM is the main component of particulate matters in environment air. Its natural sources include volcanic eruptions, sandstorms, forest and grassland fires, plants and marine sprays, and so on. Its anthropogenic sources include transportation exhaust emissions, combustion reactions, dust, kitchen cooking, cigarette burning, laser printer and so on ; (2) UPM can enter the organism through breathing and contact with the skin, and have a serious toxic effect on them.

At present, most research on UPM mainly focuses on the composition and particle size distribution characteristics related to outdoor traffic exhaust and industrial activities, and lacks understanding of the environmental behavior of UPM in indoor air. The main reasons include: (1) the health threat and environmental impact of UPM in the air are not paid enough attention. Statistics showed that air purifier penetration rate in China was only about $2 \%$, while it reached $45 \%$ in the Europe and America, and $27 \%$ in Japan; (2) the domestic air quality evaluation of UPM lacks the corresponding standards and norms. It was found that UPM seriously affected human health. Therefore, in the future we need to conduct more profound and systematic studies on the environmental behavior of UPM to provide theoretical and technical supports for air pollution control and protection.

\section{Acknowledgements}

This research was supported by the National Key R \& D Program of China (2016YFE0119600) and the Natural Science Foundation of China (No. 41877194, No.41502232).

\section{References}

1. Cassee F R, Héroux M E, Gerlofsnijland M E, et al.(2013) Particulate matter beyond mass: recent health evidence on the role of fractions, chemical constituents and sources of emission. Inhalation Toxicology, 25(14):802-812.

2. Haidong Kan, Bingheng Chen. (2004) Particulate air pollution in urban areas of Shanghai, China: healthbased economic assessment. Science of the Total Environment, 322(1):71-79.

3. Pelucchi C, Negri E, Gallus S, et al. (2009) Longterm particulate matter exposure and mortality: a review of European epidemiological studies. Bmc Public Health, 9(1):453.

4. Brown D M, Wilson M R, Macnee W, et al. (2001) Size-dependent proinflammatory effects of ultrafine polystyrene particles: a role for surface area and oxidative stress in the enhanced activity of ultrafines. Toxicology \& Applied Pharmacology, 175(3):191-199.

5. Pražnikar Z, Pražnikar J. (2012) The effects of particulate matter air pollution on respiratory health and on the cardiovascular system. Slovenian Journal of Public Health, 51(3):190-199.

6. Hitchins J, Morawska L, Wolff R, et al. (2000) Concentrations of submicrometre particles from vehicle emissions near a major road. Atmospheric Environment, 34(1):51-59.

7. Shi J P, Khan A A, Harrison R M. (1999) Measurements of ultrafine particle concentration and size distribution in the urban atmosphere. Science of the Total Environment, 235(1-3):51-64.

8. Xiao Z, Shang T, Zhuo J, et al. (2016) Study on the mechanisms of ultrafine particle formation during high-sodium coal combustion in a flat-flame burner. Fuel, 181:1257-1264.

9. Chen Y, Sheng G, Bi X, et al.(2005) Emission Factors for Carbonaceous Particles and Polycyclic Aromatic Hydrocarbons from Residential Coal Combustion in China. Environmental Science \& Technology, 39(6):1861-7.

10. Zhang Q, Gangupomu R H, Ramirez D, et al. (2010) Measurement of Ultrafine Particles and Other Air Pollutants Emitted by Cooking Activities. International Journal of Environmental Research \& Public Health, 7(4):1744-1759.

11. Van D W D, Simone G, Scheepers P T J. (2011) Nanoparticles in cigarette smoke; real-time undiluted measurements by a scanning mobility particle sizer. Analytical \& Bioanalytical Chemistry, 399(10):3573-3578.

12. Wu Chi-li,Zhang Hong-li,Guo Chang-hua, et al. (2018) Analysis of Ultrafine Particle Emission and Sink Characteristics from Side-stream Cigarette Smoke. Acta Scientiae Circumstantiae, 38(4):14101417.

13. Valente P, Forastiere F, Bacosi A, et al. (2007)Exposure to fine and ultrafine particles from secondhand smoke in public places before and after the smoking ban, Italy 2005. Tobacco Control, 16(5):312-7.

14. Zhu Weibin, $\mathrm{Hu}$ Nan, Yin Zhaoqin.(2011) Measurement and Analysis on Indoor Particle Pollution Characteristics from Printer. Environmental Science \& Technology, 34(5):104107. (in Chinese)

15. Chalupa D C, Morrow P E, Oberdörster G, et al.(2004) Ultrafine particle deposition in subjects with asthma. Environmental Health Perspectives, 112(8):879-882.

16. Stölzel M, Breitner S, Cyrys J, et al.(2007) Daily mortality and particulate matter in different size classes in Erfurt, Germany. J Expo Sci Environ Epidemiol, 17(5):458-467.

17. Liu L, Breitner S, Schneider A, et al. (2013)Sizefractioned particulate air pollution and 
cardiovascular emergency room visits in Beijing, China. Environmental Research, 121(2):52-63.

18. Fajersztajn L, Veras M, Barrozo L V, et al.(2013) Air pollution: a potentially modifiable risk factor for lung cancer[J]. Nature Reviews Cancer, 13(9):674-8. 